\title{
KONSTRUKSI REALITAS PEMILUKADA DI MEDIA ONLINE (ANALISIS FRAMING BERITA TRIBUN TIMUR ONLINE TENTANG PEMILUKADA KABUPATEN TAKALAR)
}

\author{
Rohadi Malik ${ }^{1}$, Moeh Iqbal Sultan ${ }^{2}$, Kahar $^{3}$ \\ ${ }^{1}$ Fakultas Ilmu Sosial Dan Ilmu Politik, Universitas Hasanuddin \\ email: rohadimalik@gmail.com \\ ${ }^{2}$ Fakultas Ilmu Sosial Dan Ilmu Politik, Universitas Hasanuddin \\ email: miqsul@yahoo.com \\ ${ }^{3}$ Fakultas Ilmu Sosial Dan Ilmu Politik, Universitas Hasanuddin \\ email: kaharkom@gmail.com
}

\begin{abstract}
The purpose of this study is to analyze the framework of Election of Takalar District published by Tribunnews.com. This research uses qualitative approach with constructivist paradigm, where data is interpreted according to framing theory. This research relies on framing the Takalar Regency Election published by the Tribun Timur online media. The approach of this research method is Pan and Kosicki framing analysis. The news frames analyzed are (a) syntactic structures, the way journalists construct facts. (b) the structure of the script, the way journalists relate facts. (c) thematic structure, the way journalists write facts. (d) rhetorical structure, the way journalists emphasize facts. The results showed that Tribunnews.com, raised two dominant themes about the Election of Takalar Regency, among others, the opinion of sympathizers and campaigns in the moment of Election of Takalar Regency. Framing of sympathizers 'opinions is the most prominent news category, but Tribunnews.com proportionally voices sympathizers' opinions from both Bur-Nojeng camps as petahana and rival SK-HD. The process of selecting issues is prioritized by editorial leaders in editorial meetings and journalists can take the initiative to propose a theme of news that matches reality in the field.
\end{abstract}

Keywords: Framing, Election of Takalar Regency, Tribun Timur Online

\begin{abstract}
ABSTRAK
Tujuan penelitian ini adalah: untuk menganalisis bingkai berita Pilkada Kabupaten Takalar yang dipublikasi Tribunnews.com. Penelitian ini menggunakan pendekatan kualitatif dengan paradigma konstruktivistik, dimana data diinterpretasi sesuai teori framing. Penelitian ini berfokus pada pembingkaian berita Pilkada Kabupaten Takalar yang dipublikasikan oleh media online Tribun Timur. Pendekatan metode penelitian ini adalah analisis framing Pan dan Kosicki. Kerangka berita yang dianalisis adalah (a) struktur sintaksis, cara wartawan menyusun fakta. (b) struktur skrip, cara wartawan mengisahkan fakta. (c) struktur tematik, cara wartawan menulis fakta. (d) struktur retoris, cara wartawan menekankan fakta. Hasil penelitian menunjukkan bahwa Tribunnews.com, mengangkat dua tema dominan tentang Pilkada Kabupaten Takalar antara lain opini simpatisan dan kampanye dalam momen Pilkada Kabupaten Takalar. Framing opini simpatisan adalah kategori berita yang paling menonjol, namun Tribunnews.com secara proporsional menyuarakan opini simpatisan baik dari kubu Bur-Nojeng sebagai petahana maupun rivalnya SK-HD. Proses seleksi isu merupakan hal yang diprioritaskan oleh pimpinan redaksi dalam rapat redaksi dan wartawan dapat berinisiatif mengusulkan tema pemberitaan yang sesuai realitasnya di lapangan.
\end{abstract}

Kata Kunci: Framing, Pilkada Takalar, Tribun Timur Online 


\section{PENDAHULUAN}

Pemilihan kepala daerah menjadi momentum politik yang selalu menarik perhatian publik. Bukan hanya saat Pilkada itu berlangsung, satu hingga dua tahun sebelum Komisi Pemilihan Umum Daerah (KPUD) menetapkan hari pemilihan, masyarakat sudah ramai memperbincangkan dan sekaligus memprediksi bakal calon pemimpin di daerahnya. Fenomena yang lazim dijumpai di setiap momen Pilkada misalnya komunikasi orang-orang di warung kopi, percakapan para user jejaring sosial dan media online serta perbincangan masyarakat pada umumnya, saling beradu argumen mempertahankan reputasi dan popularitas kandidatnya.

Masyarakat tergerak mengikuti arus informasi yang diterimanya baik melalui kampanye tim relawan atau tim pemenangan, pemanfaatan lembaga survey untuk pengarusutamaan wacana popularitas dan elektabilitas kandidat, dan terutama pemanfaatan media lokal dengan seluruh jaringannya. Dalam konteks ini pengemasan "isu politik" melalui media dianggap penting untuk menggiring opini publik tentang bentukan citra kandidat kepala daerah maupun incumbent yang bertarung di Pilkada.

Ibrahim (2011:190) juga berpendapat

bahwa faktor penting kesuksesan politik dewasa ini adalah dengan mengeksploitasi bebagai tawaran media untuk memproyeksikan profil seseorang sekaligus untuk memanipulasi publik. Dengan demikian dapat dikatakan kekuatan media sangat kuat (powerful) sehingga mediasi politik atau pewacanaan kepentingan para aktor politik melalui media tertentu juga sangat penting seperti ungkapan McNair (2004:3) "politics in the age of mediation", peristiwa politik, tingkah laku dan pernyataan para aktor politik, sekalipun bersifat rutin, selalu mempunyai nilai berita sehingga banyak diliput oleh media massa.

Secara objektif para wartawan dan media dalam mengkonstruksi berita politik berpedoman pada regulasi pers dan berbagai ketentuan normatif di dunia jurnalistik. Namun demikian, subjektifitas wartawan adalah suatu keniscayaan jika ditelisik adanya tendensi kepentingan ekonomi politik media yang bersangkutan. McNair (2004:16) berpendapat bahwa tidak ada selisih pendapat tentang peran sentral media dalam proses politik, dalam meneruskan dan menafsirkan peristiwa objektif dalam lingkungan politik, dan memfasilitasi persepsi subjektif dalam lingkungan publik yang lebih luas. Tegasnya McNair berkesimpulan bahwa "bias media sangatlah penting secara politis".

Pemberitaan oleh media massa adalah tindakan mengkonstruksi realitas. Hal ini karena media melihat peristiwa dari kacamata tertentu, maka informasi realitas yang diterima masyarakat adalah realitas yang telah dibentuk oleh media. Media bukanlah sebuah entitas yang bebas, karena media sendiri menjadi pelaku dalam mengkonstruksi realitas, lengkap dengan pandangan, bias dan pemihakkannya. (Eriyanto, 2002:26).

Dalam sebuah artikel "Journal of Political Communication" tentang studi kasus pemberitaan, mengatakan bahwa penonjolan adalah proses membuat informasi menjadi lebih bermakna yang mempunyai kemungkinan lebih besar untuk diperhatikan dan memengaruhi khalayak dalam memahami suatu realitas. Media dalam konteks ini menyeleksi isu tertentu dan mengabaikan isu yang lain serta menonjolkan aspek isu dengan menggunakan berbagai strategi wacana (Eriyanto, 2002:221).

Realitas pemberitaan pilkada juga dapat dicermati pada media massa online di Makassar. Tribunnews.com adalah salah satu media online yang dominan mengkonstruksi realitas peristiwa politik pra Pilkada di Kabupaten Takalar 2017. Media online tersebut lebih menonjolkan kekuatan petahana Burhanuddin Baharuddin-M.Natsir Ibrahim (Koalisi 88) dibandingkan rivalnya Syamsari Kitta-Ahmad Dg.Se're (Koalisi Kerakyatan). Dalam publikasi berita Tribunnews.com mengangkat judul dan teks berita sebagai berikut:

\section{tribunnews.com (27 Oktober 2016)}

Judul : "CRC: Meski Didera Isu Tersangka, Bur-Nojeng Sulit Dikalahkan" Latar : Sang petahana ... diterpa isu tersangka dalam kasus pemberian izin prinsip penjualan lahan negara di Desa Laikang.

Penonjolan : Isu tersebut ditengarai sulit men-downgrading elektabilitas petahana yang berjarak cukup jauh dengan sang penantang, Syamsari Kitta-H. Ahmad Dg Se're.

Pembenaran : Sulit membalikkan dukungan pemilih lebih dari 50\%. Berdasarkan data kami (Manager Riset 
Celebes Research Center) di akhir Agustus, strong voters petahana lebih dari $52 \%$," ujarnya.

Dari paparan teks di atas tampak bahwa tribunnews.com lebih cenderung memihak pada eksistensi petahana dibandingkan panantang. Hal ini terutama dapat dianalisa melalui perangkat framing, yakni pada struktur skematis, skriptural, tematik maupun struktur retoris (Eriyanto, 2002:295) sebagaimana yang dikonstruksi media online tersebut. Pada judul berita di atas menunjukkan aspek skematis dan skriptural dengan tingkat kemenonjolan yang tinggi yang menunjukkan kecenderungan berita. Wartawan tribunnews.com mengedepankan isu tentang kekuatan petahana yang diasumsikan sangat sulit dikalahakan oleh rivalnya, meskipun ia diserang dengan berbagai macam tudingan atau kampanye negatif seperti yang tampak pada kalimat "Walaupun Diterpa Isu Tersangka".

Demikian halnya pada struktur tematik dimana Pan dan Kosicki (Eriyanto, 2002:301) mengatakan berita mirip sebuah pengujian hipotesis (tema Bur-Nojeng sulit dikalahkan) dengan menyertakan sumber yang dikutip (komentar Manager Celebes Research Center, Andi Wahyudin) membuat dukungan logis bagi hipotesis yang dibuat. Selanjutnya pada struktur retoris dari wacana berita "petahana sulit dikalahkan" dengan sendirinya menggambarkan kata yang dipilih oleh wartawan media online menekankan arti yang ingin ditonjolkan bahwa meskipun petahana didera isu tersangka, Bur-Nojeng dinyatakan sulit dikalahkan. Pemakaian klaim rasionalitas hasil survey Celebes Research Center digunakan untuk mendukung pendapat petahana yang katanya sulit untuk dikalahkan.

Pembingkaian berita seperti yang dipaparkan di atas akan memengaruhi opini publik terutama user media online di wilayah Kabupaten Takalar. Para aktor politik baik petahana maupun penantang tentunya menggunakan seluruh instrumen politiknya terutama berafiliasi dengan media tertentu untuk menggulirkan wacana tentang citra positifnya dihadapan publik. Sebagai konsekuensinya, wartawan diperhadapkan dengan pilihan-pilihan fakta objektif yang akan dijemputnya di lapangan.

Dikaitkan dengan hasil liputan wartawan atas peristiwa politik pra pemilukada Kabupaten Takalar yang telah dipublikasikan
Tribunnews.com, dapat dikatakan tidak terjadi keberimbangan berita sebab yang ditonjolkan dalam narasi pemberitaan hanya menyuarakan komentar tunggal dari kubu petahana, sedangkan yang disembunyikan dari isu itu adalah pembuktian wartawan secara investigatif tentang dugaan kasus korupsi petahana. Sebagai dampaknya berita ini menjadi bias karena khalayak akan menafsirkan secara beragam makna berita itu, apakah benar ada fakta korupsi yang tersembunyi atau hanya dugaaan dari kampanye negatif yang diwacanakan oleh kubu penantang.

Berdasarkan uraian latar belakang di atas penulis bermaksud menganalisis teks berita online pada tribunnews.com tentang pembingkaian berita pemilihan kepala daerah di Kabupaten Takalar. Fokus berita online yang dianalisis menggunakan pendekatan analisis teks media khususnya framing analysis model teoretis Zhongdang Pan dan Gerald M.Kosicki. Pendekatan analisis pembingkaian yang dimaksudkan lebih mendalami temuan awal peneliti tentang penonjolan isu politik dalam peristiwa Pilkada yang dipublikasikan oleh tribunnews.com. Adapun tujuan yang akan dicapai adalah untuk mengetahui realitas Pilkada Kabupaten Takalar dalam pemberitaan Tribunnews.com.

\section{KAJIAN LITERATUR}

\section{JURNALISTIK ONLINE}

Nuruddin (2011:6) yang mengutip kamus Oxford Advanced Learners Dictionary of Current English, mengemukakan; "the work of profession of producing; writng for journal and newspaper" yaitu profesi yang berkaitan dengan memproduksi tulisan untuk jurnal dan surat kabar.

Dalam perspektif hukum pers Indonesia (UU RI No. 40 Tahun 1999, Tentang Pers) kegiatan jurnalistik meliputi mencari, memperoleh, memiliki, menyimpan, mengolah dan menyampaikan informasi baik dalam bentuk tulisan, suara, gambar, suara dan gambar, serta data dan grafik maupun dalam bentuk lainnya dengan menggunakan media cetak, media elektronik dan segala jenis saluran yang tersedia (Nuruddin, 2011:321).

Berdasarkan definisi tersebut di atas maka pengertian jurnalistik adalah keterampilan atau kegiatan mengulang bahan berita mulai dari peliputan sampai kepada 
penyusunan yang layak disebarluaskan kepada masyarakat. Adapun keterampilan itu sendiri meliputi kegiatan mencari, mengumpulkan, menyeleksi dan mengolah informasi yang mengandung nilai berita serta menyajikan kepada khalayak melalui media massa periodik baik cetak maupun eletronik.

\section{TEORI KONVERGENSI MEDIA}

Nicholas Negroponte adalah yang pertama kali memopulerkan istilah konvergensi tahun 1979 di Massachusetts Institute of Technology (MIT). Negroponte mengatakan bahwa semua teknologi komunikasi bersamasama sedang memasuki titik genting metamorfosis, yang hanya dapat dipahami dengan tepat jika didekati sebagai subjek tunggal. Untuk memberikan gambaran ini Negroponte membuat tiga lingkaran yang tumpah tindih yang diberi nama, 1) industri penyiaran dan gambar hidup, 2) industri komputer, dan 3) industri penerbitan dan penyiaran.

Lima dimensi Grant dan Wilkinson dapat dijadikan variabel analisis pelaksanaan konvergensi di sejumlah industri media. Kelima dimensi konvergensi versi Grant tersebut adalah sebagai berikut:

1) Konvergensi teknologi. Dalam konvergensi, teknologi tidak selalu dianggap sama pentingnya dengan faktor organisasi, faktor sosial, dan faktor pemakai (user) dalam analisis media. Perkembangan teknologi yang menjadi inti dari konvergensi media adalah teknologi digital dan jaringan komputer.

2) Konten multimedia. Konten multimedia ini tercermin dalam pengelolaan newsroom dan website. Di sini telah terjadi revolusi mendasar, yaitu outlet-outlet media tradisional berubah menjadi outlet digital dalam bentuk web. Kondisi lainnya adalah bagaimana newsroom tradisional yang dipadati dengan beraneka mesin dan jurnalis menjadi newsroom yang lebih efisien dengan hasil berita yang lebih optimal dan dilengkapi dengan teknologi digital yang lebih canggih.

3) Kepemilikan. Dimensi ini membahas konvergensi media berdasarkan kepemilikan yang mengarah pada kesamaan entitas (co-ownership). Dengan adanya kepemilikan yang satu maka media-media yang bernaung di bawahnya dapat melakukan content sharing yang lebih efektif dan hal ini juga berkaitan dengan motif ekonomi-politik di mana setiap pemilik media memiliki keinginan untuk menjadi pengaruh dalam masyarakat.

4) Kolaborasi. Tidak semua media melakukan co-ownership untuk menunjang performanya. Beberapa media memilih melakukan kolaborasi dengan media lainnya, seperti kolaborasi penerbit, editor dan news director dengan tujuan untuk memenangkan persaingan pasar.

5) Koordinasi. Media-media yang tidak melakukan co-ownership dan kolaborasi biasanya menempuh langkah koordinasi yang didasari pada motif ekonomis, sematamata demi memperkuat posisi media tersebut terhadap kompetitornya.

\section{TEORI MEDIA BARU}

Istilah media baru (new media) pada awalnya mengandung arti negletik (penolakan); media baru bukan media massa, terutama televisi. Sifat media baru adalah cair (fluids), konektivitas individual dan menjadi sarana untuk membagi peran kontrol dan kebebasan. Media baru merujuk pada perkembangan teknologi digital namun media baru sendiri tidak serta merta berarti media baru. Video, teks, gambar, grafik yang diubah menjadi datadata digital berbentuk byte, hanya merujuk pada sisi teknologi mutlimedia, salah satu dari unsur dalam media baru adalah memiliki ciri interaktif dan intertekstual.

Mengangkat isu jurnalistik di media baru, berarti mengangkat pertanyaan baru tentang medium (saluran). J.V Pavlik menulis bahwa jika koran merupakan medium bagi editor dan televisi merupakan medium bagi produser, maka internet sebagai satu bentuk media baru merupakan medium bagi para jurnalis. Internet tidak hanya memiliki semua kemampuan yang selama ini dimiliki oleh media massa konvensional (teks, images, grafis, video ataupun audio) tetapi juga menawarkan spektrum yang lebih luas, seperti interaktivitas, akses mandiri, kontrol pengguna dan personalisasi.

Tahapan perkembangan isi berita dalam edisi online internet menurut Pavlik telah melewati tiga tahap sebagai berikut: 
a. Surat kabar online hanya memindahkan ulang versi cetaknya ke online (repurpose content from their mother ship).

b. Surat kabar sudah membuat isi inovatifkreatif dalam websitenya dengan fitur interaktif seperti hyperlinks dan search engines, yang dapat memudahkan pengguna mencari materi dengan tema khusus yang sesuai dengan ukuran kebutuhannya, misalnya dengan katagori berita dan informasi yang dipilihnya.

c. Ketiga, isi berita telah didesain secara khusus untuk media web sebagai sebuah medium komunikasi.

\section{BERITA DALAM PARADIGMA KONSTRUKTIVIS}

Dalam Ensiklopedi Pers Indonesia, definisi berita adalah laporan atau pemberitahuan mengenai terjadinya peristiwa atau keadaan yang bersifat umum dan baru saja terjadi (aktual) yang disampaikan oleh wartawan dalam media massa (Junaedhie, 1991:26). Secara terminologi, belum ada kesepakatan oleh para ahli tentang definisi berita yang baku. Northclife mendefinisikan berita dengan ungkapan klasiknya (if a dog bites a man, it is not news. But if a man bites a dog is a news). Jika anjing menggigit orang, itu bukan berita. Tetapi jika manusia menggigit anjing itulah berita (Romli, 2006:2).

Teori konstruksi sosial berada di antara teori fakta sosial dan defenisi sosial. Dalam teori fakta sosial, struktur sosial yang eksis merupakan faktor penting. Manusia adalah produk dari masyarakat. Tindakan dan persepsi manusia ditentukan oleh struktur yang ada dalam masyarakat, institusionalisasi, norma, struktur dan lembaga sosial menentukan individu manusia. Demikian sebaliknya, teori defenisi sosial menyatakan bahwa manusialah yang membentuk masyarakat. Manusia digambarkan sebagai entitas yang otonom melakukan pemaknaan dan membentuk masyarakat. Manusia yang membentuk realitas, menyusun institusi dan norma yang ada (Eriyanto, 2002:13).

Pendekatan konstruktivis mempunyai penilaian tersendiri bagaimana media, wartawan, dan peristiwa dilihat kemudian dikonstruksi menjadi berita. Pada intinya, fakta-peristiwa adalah hasil konstruksi. Karena itu, realitas bersifat subjektif dan tidak ada realitas yang objektif. Realitas hadir karena dihadirkan oleh konsep subjektif wartawan. Realitas tercipta lewat konstruksi, yakni sudut pandang tertentu dari wartawan. Realitas bias bebeda-beda, tergantung pada bagaimana konsepsi ketika realitas itu dipahami oleh wartawan yang juga mempunyai pandangan berbeda (Eriyanto, 2002:19).

\section{MEDIA DAN KOMUNIKASI POLITIK}

\section{Peran Media dalam Politik}

Media dapat memainkan peranan yang sangat besar khususnya pada saat transisi politik, karena media dapat bertindak sebagai agen perubahan. Neuman mengatakan bahwa kebebasan memegang peranan penting di Asia Tenggara, khususnya dalam proses liberalisasi politik yang berhubungan dengan munculnya pers yang lebih terbuka dan kritis.

a. Stabilitas. Terkait fungsi yang ditunjukkan oleh media sebagai institusi politik dapat dilihat pada rezim Soeharto yang mempromosikan ideologi nasional dan melegitimasi proses pembangunan. Dalam menjalankan fungsi ini, pers adalah sebagai sebuah agen stabilitas, yang bertugas membantu melestarikan tatanan sosial politik. Fungsi ini umumnya berkaitan dengan istilah development journalism.

b. Pengendalian. Fungsi kedua adalah memonitor tatanan politik pada masa damai, melakukan mekanisme checks and balances. Cook (2000:4) mengemukakan beberapa hal. Pertama, para wartawan telah bekerja keras untuk mendorong masyarakat agar tidak berpikir bahwa mereka adalah aktor politik. Kedua, studi mengenai komunikasi politik berkembang di tengahtengah sebuah tradisi yang menekankan efek media, dan disiplin ilmu yang terkait dengan studi politik tentang media berita pun telah pula menyembunyikan implikasi dari kegiatan mereka. Pada umumnya, ketika pakar politik merasa nyaman dengan melihat konstribusi politik dari media, maka mereka menjadi kurang memiliki keinginan untuk melihat media berita sebagai sebuah institusi. Dengan kata lain, para wartawan telah berhasil meyakinkan kalangan akademisi, bahwa mereka bukan aktor politik, dan para peneliti yang 
membahas tentang studi politik maupun media telah melalaikan hal ini.

c. Perubahan. Dalam konteks ini media sebagai fire-fighting, yaitu membantu dalam menentukan hasil dari perubahan politik dan sosial dramatik yang terjadi saat krisis. Contoh pada rezim orde baru dapat menunjukkan hal ini, yakni peran media dalam menggulingkan rezim Soeharto, atau dukungan yang ditunjukkan pers pada demonstrasi pro-demokrasi pada 19981999. Dalam fungsi ketiga ini, pers merupakan agen perubahan (agent of change).

\section{KOMUNIKASI POLITIK MODEL BRIAN MCNAIR}

Komunikasi politik dalam konsepsi McNair lebih mempertajam area studinya ke dalam tiga unsur yang bertujuan memahami tindakan politik, yakni relasi antara media, organisasi politik dan warga.

Inti pandangan McNair tentang studi komunikasi politik adalah eksistensi tindakan pelaku politik yang termediasi. Dalam konteks ini organisasi media, organisasi politik atau politisi dan publik dilihat dalam hubungan yang dialektis. Analisis McNair yang lebih gamblang adalah pembuktian empiris soal afiliasi politik partai dengan media, demikian pula sebaliknya media dinyatakan memiliki peran signifikan sebagai "pelaku politik" dengan menjelaskan bermacam cara media-misalnya mendefinisikan realitas politik-untuk memengintervensi proses politik (McNair,2016:75-84 dan 101-126).

\section{PENDEKATAN ANALISIS TEKS MEDIA}

\section{Teori Framing}

Menurut Sudibyo, konsep tentang framing atau frame sendiri bukan murni konsep ilmu komunikasi, akan tetapi dipinjam dari ilmu kognitif (psikologis). Dalam praktiknya, analisis framing juga membuka peluang bagi implementasi konsep-konsep sosiologis, politis, dan kultural untuk menganalisis berdasarkan konteks sosiologis, politis, atau kultural yang melingkupinya (Sobur, 2012:168).

G.J. Aditjondro mendefenisikan framing sebagai metode penyajian realitas di mana kebenaran tentang suatu kejadian tidak diingkari secara total, melainkan dibelokkan secara halus, dengan memberikan sorotan terhadap aspek-aspek tertentu saja, dengan menggunakan istilah-istilah yang punya konotasi tertentu, dan dengan bantuan foto, karikatur, dan alat ilustrasi lainnya (Eriyanto, 2002:165).

Keempat struktur tersebut merupakan suatu rangkaian yang dapat menunjukkan framing dari suatu media. Kecenderungan atau kecondongan wartawan dalam memahami suatu peristiwa dapat diamati dari keempat struktur tersebut. Dengan kata lain ia dapat diamati bagaimana wartawan menyusun peristiwa kedalam bentuk umum berita, cara wartawan mengisahkan peristiwa, kalimat yang dipakai, dan pilihan kata atau idiom yang dipilih.

\section{METODE PENELITIAN}

Objek penelitian adalah teks pemberitaan piilkada takalar pada tribun timur online, Penelitian ini dilakukan mulai dari bulan November 2016 sampai bulan April 2017 dan bertempat di redaksi Tribun Timur Online, Jalan Cendrawasih No. 430 Makassar.

Tipe penelitian ini adalah kualitatif dengan paradigma konstruktivistik. Penelitian ini bisa juga disebut penelitian interpretatif, karena data hasil yang dikumpulkan merupakan interpretasi terhadap data dari objek penelitian (Bungin, 2008). Penelitian ini berfokus pada pembingkaian berita politik tentang Pilkada Kabupaten Takalar yang dipublikasikan oleh media online Tribun Timur. Sementara itu, pendekatan metodologis penelitian ini adalah analisis framing model Zhongdang Pan dan Geral M.Kosicki yang memodifikasi dimensi operasional Critical Discourse Analysis model van Dijk (Sobur, 2006:175-176).

Adapun sumber data dalam penelitian ini adalah data primer yang digunakan dalam penelitian ini adalah teks berita terkait pemberitaan pemilukada Kabupaten Takalar yang dipublikasi oleh Tribuntimur.com.

Data primer dalam penelitian ini menggunakan langkah-langkah analisis framing dengan model Pan dan Kosicki, dengan mengoperasionalisasikan empat dimensi struktural teks berita sebagai perangkat framing: sintaksis, skrip, tematik dan retoris. Sedangkan data sekunder diperoleh dari kajian pustaka, mencari rujukan teoritis yang relevan dengan cara membaca buku, surat kabar, majalah, hasil-hasil penelitian, maupun browsing internet yang sesuai dengan kajian 
penelitian serta data-data yang diperoleh dari pihak media tribun-timur.com.

\section{HASIL PENELITIAN DAN PEMBAHASAN}

\section{HASIL PENELITIAN}

Berdasarkan hasil penelusuran data berita Tribunnews.com, ditemukan beberapa sampel berita yang secara spesifik mengangkat tema tentang Pilkada Kabupaten Takalar. Data berita Tribunnews.com menunjukkan beberapa kategori berdasarkan konteks peristiwa Pilkada Kabupaten Takalar, antara lain mengenai opini simpatisan dan kandidat, pemuka pendapat (opinion leader), kampanye politik dan beberapa peristiwa lainnya dalam momentum Pilkada Kabupaten Takalar.

\section{Analisis Berita Kategori Opini Simpatisan}

Berikut diuraikan skema pembingkaian Tribunnews.com berdasarkan model analisis Pan dan Kosicki terkait publikasi berita dengan kecenderungan menarasikan opini masingmasing simpatisan dari kedua kubu yang bertarung di Pilkada Kabupaten Takalar.

\section{Analisis Berita Kategori Kampanye Politik}

Tribunnews.com

banyak

mempublikasi peristiwa kampanye Pilkada Takalar karena kegiatan ini yang paling dominan dilakukan oleh tim pemenangan kandidat dan para relawan menjelang pemungutan suara. Dalam proses kampanye inilah para simpatisan berupaya mensosialisasikan pesan politik para kandidat, baik secara langsung dengan melakukan kampanye komunikatif atau interaksi dan dialog langsung dengan pemilih maupun kampanye politik yang dikonstruksi melalui berita. Seperti halnya berita bertema komentar simpatisan, peristiwa kampanye yang dilakukan oleh tim pemenangan Bur-Nojeng dan tim pemenangan SK-HD juga ditampilkan secara bergantian pada seluruh berita yang dipublikasi Tribunnews.com.

\section{PEMBAHASAN}

\section{KATEGORI OPINI SIMPATISAN}

\author{
Struktur Sintaksis \\ Dalam momentum kampanye dan \\ pasca Pilkada 15 Februari 2017, pembaca
}

Tribunnews.com mengharapkan adanya wacana dari masing-masing kubu yang di dalam ranah media disebut sebagai unsur keberimbangan berita (cover both side). Namun dari aspek headline, lead dan tubuh berita, cenderung lebih menonjolkan opini dari kubu Bur-Nojeng meski secara berlawanan juga mewacanakan komentar dari SK-HD. Konstruksi headline Tribunnews.com ini didukung dengan lead sebagaimana kutipan berita berikut ini:

Duta Politika Indonesia Door To Door untuk Bur-Nojeng. Duta Politika Indonesia (DPI) bakal ikut menurunkan relawan untuk memenangkan pasangan Calon Bupati dan Wakil Bupati Takalar, Bur-Nojeng.

Tenri Olle Sebut Syamsari Kitta-Achmad Daeng Se're Calon Bupati Bersih. Wakil Ketua DPW Partai Nasdem Sulsel Tenri Olle Yasin Limpo mengumpulkan seluruh pengurus DPD dan DPC Nasdem Takalar di Rumah Juang Pattalassang, Kabupaten Takalar (1/11/2016).

Lead yang dirangkai bersama tubuh
berita di atas dikonstruksi oleh Tribunnews.com dalam konteks waktu yang sama atau merupakan kelanjutan peristiwa pada hari sebelumnya. Lead pada point pertama di atas menunjukkan dua peristiwa yang hampir sama, yakni keterangan simpatisan Bur-Nojeng yang lebih menekankan basis kekuatan politik yang didukung oleh tim relawan (DPI) dan koalisi partai besar yaitu Golkar, Demokrat, PAN, PPP, Hanura, Gerindra, dan PKPI. Lead ini menunjukkan makna pencitraan kandidat dari segi kekuatan kendaraan politiknya, sementara wacana dari kubu SK-HD juga menojolkan komentar politisi, Tenri Olle Yasin Limpo yang mengklaim adanya support total dari keluarga besar Yasin Limpo untuk pasangan SK-HD. Berikut dipaparkan tekstualitas dari tubuh berita yang menyertakan komentar simpatisan dari masing-masing kubu:

\footnotetext{
Simpatisan Bur-Nojeng: Jadi namanya ini Relawan Door To Door Bur-Nojeng, kita akan turun kan langsung ke 9 kecamatan dan 100 desa, ujar Direktur Eksekutif DPI Dedy Alamsyah Mannaroi ... Bur-Nojeng mendapatkan dukungan dari Partai Golkar, Demokrat, PAN, PPP, Hanura, Gerindra, dan PKPI (1/11/2016).
} 
Simpatisan SK-HD: Apapi lagi, konsep kita bagus, diterima semua masyarakat, calon kita ini bersih, pergerakan kita massif. Sisa bagaimana menjaga ritme pergerakan hingga di hari pencoblosan nanti, kata Tenri Olle ... Saya sudah kasi ketemumi SK-HD dengan adik-adik dan ponakan-ku. Tenangmi saja, Insyaallah keluarga kami di Takalar akan mendukung sepenuhnya. Sekedar teman-teman tau saja, pertemuan-pertemuan di keluarga kami sudah selesai (1/11/2016).

Lead dan tubuh berita pada berita lainnya juga menunjukkan klarifikasi dari masing-masing kubu atas menyebarnya isu kampanye hitam terhadap kandidat mereka. Komentar simpatisan dari kubu SK-HD membantah tudingan bahwa kelompoknya telah memfitnah petahana melalui selebaran yang dibagikan kepada masyarakat, sedangkan komentar narasumber simpatisan Bur-Nojeng juga menyangkal dugaan mobilisasi PNS dalam proses kampanye mereka. Berikut diuraikan teks dari tubuh berita tentang komentar klarifikasi masing-masing simpatisan yang ditempatkan di awal, tengah dan akhir paragraf berita sebagaimana kutipan teks berikut:

\begin{abstract}
Simpatisan Bur-Nojeng: Bahkan pada waktu calon kami mengambil cuti, kita sudah himbaukan ASN agar bersikap netral di Pilkada Takalar ... Kalaupun dia hadir di kampanye kita, saya kira tidak ada masalah, sepanjang ASN tersebut tidak menggunakan atribut ASN, simbol dan sebagainya atau ASN melakukan kampanye menangkan pasangan calon (7/11/2016).

Simpatisan SK-HD: Isu korupsi itu menjadi tema bersama, kita perangi sama-sama, jangan asal bicara, kata Hairil ... Disebut fitnah kalau informasi yang sebar sumbernya tidak akurat. Info pemeriksaan di Kejati tersebar luas di media online dan cetak, ucap Ketua PKS Takalar tersebut (1/12/2016).
\end{abstract}

Lead dan tubuh berita di atas menampilkan peristiwa tentang reaksi politik dari masing-masing kubu. Jika berita sebelumnya menampilkan bentuk sanggahan atau klarifikasi para simpatisan terhadap isu black campaign, maka berita selanjutnya lebih menunjukkan propaganda satu pihak dan serangan politik di pihak lain.

Dari kedua kategori bingkai berita tersebut diketahui bahwa yang menjadi latar peristiwa dari pemberitaan Tribunnews.com, yaitu tentang upaya kelompok simpatisan mencitrakan kandidatnya masing-masing dan berbagai bentuk reaksi politik terhadap propaganda atau sebaran isu kampanye hitam. Jika dicermati secara keseluruhan, maka dalam level sintaksis berita tersebut memiliki keterkaitan antara satu peristiwa dengan persitiwa lainnya yang dibingkai dari sudut pandang masing-masing simpatisan sebagai narasumber berita Tribunnews.com.

Kutipan wawancara narasumber dalam hal ini merupakan bagian penting dalam teks berita yang perlu dicermati, dimana Tribunnews.com memunculkan argumentasi dari masing-masing kubu yang bertarung dalam Pilkada Takalar termasuk pernyataan pihak yang dianggap netral, misalnya komentar kalangan birokrat, PLT Bupati Takalar (Darmawan Bintang) dan Ketua Korpri Takalar (Nirwan Nasrullah), terkait kasus dugaan petahana memobilisasi PNS dalam proses kampanye. Komentar dari kalangan birokrat ini tentu memiliki kekuatan legitimasi dengan cara memaparkan ketentuan hukum jika ada ASN yang terbukti terlibat terlibat politik praktis.

\section{Struktur Skrip}

Secara garis besar teks dengan kategori "komentar simpatisan" (Tabel 2 dan Tabel 3) telah memenuhi unsur kelengkapan berita $(5 \mathrm{~W}+1 \mathrm{H})$ meskipun ditemukan sebagian berita yang tidak lengkap dari aspek where atau dimana tempat wawancara dengan narasumber dilakukan. Seperti yang dijelaskan terdahulu, Tribunnews.com menyusun berita tersebut dari fakta peristiwa yang bebeda namun terjadi di hari yang sama atau menunjukan hubungan kausalitas (sebab-akibat) dari satu peristiwa ke peristiwa yang lain. Demikian pula dengan tempat peristiwa yang diliput wartawan Tribunnews.com, menunjukkan perbedaan tempat masing-masing objek/subjek pemberitaan.

\section{Struktur Tematik}

Elemen tematik berita Tribunnews.com pada Tabel 2 dan Tabel 3 menunjukkan tema tentang "pencitraan kandidat" dan "klaim kebenaran" dari masingmasing kelompok simpatisan. Tema pencitraan kandidat misalnya didukung dengan komentar simpatisan bahwa kandidat mereka memiliki basis kekuatan baik secara individual maupun dari aspek dukungan partai dan lembaga lain. Kecenderungan yang tampak dari komentar 
simpatisan Bur-Nojeng adalah mengedepankan citra petahana dengan basis dukungan koalisi partai besar serta program-programnya yang bertema kerakyatan. Sementara itu komentar simpatisan SK-HD lebih cenderung memanfaatkan suara opinion leader yang melegitimasi citra kandidatnya sebagai "calon bupati bersih".

Tema pencitraan dan klaim kebenaran selanjutnya diobjektivasi melalui pengungkapan argumentasi dari masingmasing simpatisan dan juga komentar dari narasumber yang netral atau kalangan akadimisi, birokrat dan tokoh masyarakat sebagai opinion leader. Hal ini dilihat dalam elemen detil dan koherensi teks yang dikonstruksi Tribunnews.com. Teks dari sampel berita pada Tabel 2 dan Tabel 3 secara proporsional disusun dengan detil paragraf pendek maupun panjang.

Namun dilihat secara keseluruhan detil paragraf berita Pilkada Takalar yang dipublikasi Tribunnews.com berbeda dengan versi cetaknya (surat kabar Tribun Timur), sebab kalimat berita online cenderung lebih ringkas lazimnya hanya satu sampai tiga paragraf. Kalimat ringkas dalam paragraf berita Tribunnews.com sudah menjadi kecenderungan umum jika mencermati ragam konten berita online lainnya. Akan tetapi perspektif framing melihat hal itu sebagai bagian dari proses seleksi, penonjolan dan membuang fakta peristiwa tertentu yang erat kaitannya dengan agenda kebijakan redaksional media.

\section{Struktur Retoris}

Konstruksi berita pada Tabel 2 dan Tabel 3 dengan tema tentang "pencitraan kandidat" dan "klaim kebenaran" menunjukkan adanya penekanan-penekanan pada level retoris. Misalnya, pemilihan kata "dukungan partai" dari ucapan narasumber Duta Politika Indonesia (DPI), Dedy Alamsyah, bermakna mengasosiasikan citra petahana dengan kekuatan partai besar yang mendukungnya. Dalam perspektif komunikasi politik, tentunya retorika atau politik bahasa menjadi sangat penting sebagai strategi untuk memengaruhi opini publik tentang citra kandidat.

Selain pemilihan kata (leksikon), Tribunnews.com juga menampikan unsur metafora dalam tema berita tentang "pencitraan kandidat" dan "klaim kebenaran". Metafora yang dimaksud adalah kalimat "door to door" sebagaimana yang dituturkan oleh simpatisan dari kedua kubu dalam teks berita. Metafora "dari pintu ke pintu" dalam hal ini merupakan atribusi simbolik untuk model kampanye masing-masing tim pemenangan kandidat. Konstruksi teks berita tersebut menunjukkan bahwa kedua tim pemenangan memiliki pola kampanye yang sama dengan melibatkan seluruh kader partai di daerah dan bantuan relawan untuk menyasar rumah-rumah warga Takalar. Kalimat metafora itu secara definitif diartikan oleh simpatisan Bur-Nojeng sebagai aksi "turun langsung ke 9 Kecamatan dan 100 Desa", sedangkan simpatisan SK-HD mengartikulasinya "minimal 20 rumah setiap hari, diketuk dan diyakinkan untuk memilih SK-HD”.

Dimensi retoris lainnya yang menonjol pada berita ini adalah headline. Pemakaian huruf tebal (bold) dan berukuran relatif besar pada seluruh headline berita Pilkada Takalar yang dipublikasikan Tribunnews.com. Selain headline dan subjudul, dimensi retoris lainnya dalam berita Pilkada Takalar adalah elemen grafis atau gambar yang ditampilkan Tribunnews.com sebagai bagian dari objektivitas berita seperti gambar 2 dan 3 .

\section{KATEGORI KAMPANYE POLITIK Sintaksis}

Dua judul pada Tabel 4 dan Tabel 5 menegaskan substansi pesan kampanye yang berbunyi "Janji Naikkan Tunjangan PNS dan Kepala Desa" dan "Warga Takalar Antusias Sambut Kartu Berua Baji”. Konstruksi headline Tribunnews.com ini didukung dengan lead dan latar peristiwa sebagaimana kutipan teks berita berikut ini:

\begin{abstract}
Janji Kampanye Bur-Nojeng di Galesong Utara. Incumbent Pilkada Takalar, Burhanuddin Baharuddin- M Natsir Ibrahim (Bur-Nojeng) kampanye di Desa Bontolebang, Kecamatan Galesong Utara, Minggu ... Pusat pendaratan ikan ini akan lebih besar dan lebih maju karena sangat dekat dengan makassar sehingga berpotensi untuk berkembang sangat besar apalagi pelelangan ikan yang di Rajawali telah ditutup(20/11/2016).
\end{abstract}

Syamsari Kitta Janji Naikkan Tunjangan PNS dan Kepala Desa. Satu lagi program 
pasangan calon bupati dan wakil bupati nomor urut 2 Syamsari Kitta-Ahmad Se're ... Kita berani naikkan tunjangan ASN dan perangkat desa 100 persen adalah wujud keseriusan kami(26/11/2016)

Lead di atas dirangkai bersama tubuh berita dengan latar peristiwa yang sama sebagai bentuk penyampaian fakta orasi politik dua kandidat ketika berkampanye di daerah Takalar. Pernyataan narasumber dalam hal ini merupakan bagian penting dalam teks berita yang perlu dicermati. Berita pertama di atas, menempatkan latar persitiwa pada bagian akhir paragraf berita dengan cara mengutip orasi politik Burhanuddin yang berjanji membangun Pusat Pendaratan Ikan (PPI) di Beba, Desa Bonto lebang jika kembali terpilih. Tubuh berita pada point kedua juga menempatkan latar persitiwa pada bagian akhir paragraf berita yang menarasikan janji politik kandidat Syamsari Kitta, menaikkan tunjangan ASN serta perangkat desa hingga 100 persen.

Selain menonjolkan orasi politik para kandidat, Tribunnews.com juga menyajikan narasi kelompok kepentingan dalam berita bertema kampanye politik. Kelompok kepentingan yang dimaksud adalah Partai yang mengusung kandidat yang umumnya bergabung dalam struktur tim pemenangan.

\section{Skrip}

Dua teks berita pada Tabel 4 dan Tabel 5 menunjukkan bahwa masing-masing berita memaparkan fakta kampanye Pilkada Takalar versi kelompok Bur-Nojeng maupun kampanye dari kubu SK-HD. Namun dilihat dari aspek kelengkapan skrip, Tribunnews.com cenderung membangun narasi tunggal karena berita Pilkada yang ditampikan hanya mengutip satu atau dua pandangan narasumber dari pihak yang diwacanakan dalam berita.

Berbeda dengan skrip pada surat kabar yang umumnya menampilkan narasi dialogis dalam beritanya, dimana elemen who tidak hanya opini narasumber atau pihak yang berkampanye, melainkan sering ditampilkan komentar pengamat atau pihak yang dianggap kompeten mengomentari peristiwa kampanye, termasuk suara warga yang hadir atau terlibat dalam kampanye tersebut sehingga tidak menimbulkan kesan pemberitaan satu arah tetapi lebih dialogis dan komunikatif.

Dari penjabaran elemen skrip berita tersebut menunjukkan adanya perbedaan konteks peristiwa Pilkada yang disampaikan Tribunnews.com. Teks berita pada Tabel 4 dan Tabel 5 sama-sama menyampaikan janji politik para kandidat ketika mereka melakukan kampanye di daerah Takalar. Adapun masingmasing berita itu hanya menampilkan opini tunggal dari narasumber untuk menopang objektivitas pemberitaan.

\section{Tematik}

Elemen tematik (detail, maksud, nominalisasi, koherensi, bentuk kalimat dan kata ganti) menunjukkan makna global dalam teks berita dimana tema utama yang menonjol pada Tabel 4 dan Tabel 5 adalah kampanye politik personal kandidat maupun kampanye kolektif dari partai pengusung atau tim pemenangan. Tema kampanye ini didukung dengan cara penulisan berita oleh Tribunnews.com tentang pewacanaan opini kandidat mengenai janji politiknya kepada rakyat yang tertuang dalam program serta visimisi, maupun konsep atau rencana aksi kampanye bentukan partai pengusung masingmasing kandidat. Elemen tematik yang dipakai Tribunnews.com diantaranya adalah detil dan koherensi. Deskripsi tekstual tentang kampanye politik kandidat Bur-Nojeng dan SK-HD saat mereka berkampanye diuraikan dengan detil kalimat yang relatif proporsional atau seimbang.

Khususnya judul berita "Menangkan Bur-Nojeng, Parpol Pengusung Gencar Konsolidasi ke Level Terendah", Tribunnews.com mencoba menetralkan pendapat partai pengusung dan Jubir kandidat Bur-Nojeng yang nyata lebih dominan dalam teks berita karena diurai dengan detil kalimat atau paragraf yang panjang dengan penekanan kata konsolidasi partai-partai besar (Golkar, Hanura, Demokrat, PPP, Gerindra, PAN, PDIP, PBB, dan PKPI). Di akhir paragraf dituangkan opini tim pemenangan SK-HD sebagai bagian dari koherensi yang mengungkap fakta lain bahwa warga pendukung pasangan Bur-Nojeng mengalihkan dukungannya kepada SK-HD di Pilkada Takalar.

Koherensi Pembeda ... Terpisah, Ketua Tim Media pasangan Syamsari Kitta-Achmad Deang Se're (SK-HD) Hairil Anwar mengungkapkan sejumlah pendukung pasangan Bur-Nojeng mendukung SK-HD di Pilkada Takalar.Contohnya, kemarin itu masyarakat Bonto Kaddato ramai-ramai jalan 
kaki mengantar Pak Syamsari Kitta ke lokasi kampanye. Dihalaman rumah Daeng Tona, mereka mengaku berada dikubu sebelah dan Pilkada kali ini dia beralih dukungan ke SKHD, " kata Haeril kepada sejumlah awak media ... mereka juga berkomitmen akan memenangkan Pak Syamsari di Kelurahan Bonto Kaddatto. (29/11/2016).

Hubungan antarkalimat dalam berita tersebut di atas dilihat pada koherensi pembeda. Ada dua opini narasumber yang berbeda namun dirangkaikan ke dalam satu kesatuan teks berita "Menangkan Bur-Nojeng", antara lain, (1) pernyataan Ketua DPC Partai Hanura Kabupaten Takalar, Ilham Jaya Torada dan kader PPP sekaligus Juru bicara pasangan BurNojeng Jilid II, Makmur Mustakim (2) Ketua Tim Media SK-HD Hairil Anwar. Berdasarkan hasil analisis, rangkaian tematik pada berita Tribunnews.com kategori kampanye politik menerangkan bahwa masing-masing kandidat Pilkada Takalar menyuarakan janji politik kepada rakyat, demikian halnya partai pengusung juga menunjukkan kekuatan mesin politiknya masing-masing dalam proses kampanye yang tengah berlangsung.

\section{Retoris}

Pada level retoris, terdapat penekanan kata dan kalimat dalam teks berita kategori kampanye Pilkada Takalar yang dipublikasi Tribunnews.com. Adapun penekanan kata yang dimaksud adalah pemakaian huruf tebal dan berukuran relatif besar pada setiap headline atau judul berita. Strategi ini juga lazim dilakukan oleh Tribun Timur versi surat kabar, dengan tujuan menarik perhatian pembaca maka judul dibuat singkat, padat dan ukuran teksnya dibesarkan atau ditebalkan. Selain itu kata "Menangkan" sebagai pilihan kata (leksikon) dimaknai secara berbeda. Kata "Menangkan" diartikulasikan oleh kader PKS secara lebih konkrit yakni mengirim 15 kader terbaiknya ke Takalar untuk memenangkan SKHD, sedangkan kader partai Hanura/PPP menekankan kata "konsolidasi lintas partai" yang sifatnya abstrak atau bukan tindakan yang lebih praktis untuk untuk memenangkan BurNojeng. Selain penekanan pada aspek grafis dan leksikon, Tribunnews.com juga menampilkan dimensi retoris lainnya dari pemberitaan tentang kampanye politik dalam Pilkada Takalar sebagaimana tampilan gambar 4 dan 5 .

\section{KESIMPULAN}

Berdasarkan penelitian mengenai Konstruksi Realitas Pemilukada di Media Online (Analisis Framing Berita Tribun Timur Online tentang Pemilukada Kabupaten Takalar), maka diperoleh kesimpulan sebagai berikut :

Hasil analisis data penelitian ini menunjukkan bahwa Tribunnews.com, mengangkat dua tema dominan tentang Pilkada Kabupaten Takalar antara lain mengenai opini simpatisan dan kandidat dan kampanye politik dalam momentum Pilkada Kabupaten Takalar. Framing opini simpatisan adalah kategori berita yang paling menonjol, namun Tribunnews.com secara proporsional menyuarakan opini simpatisan baik dari kubu Bur-Nojeng sebagai petahana maupun rivalnya SK-HD. Framing peristiwa kampanye Pilkada Takalar dalam berita Tribunnews.com adalah orasi politik para kandidat dan kegiatan tim pemenangan kandidat atau para relawan untuk mensosialisasikan pesan politik para kandidat, yang dikonstruksi melalui berita. Dalam hal ini Tribunnews.com menyajikan narasi kelompok kepentingan dalam berita bertema kampanye politik.

\section{REFERENSI}

Bungin, M. Burhan. 2008. Penelitian Kualitatif. Jakarta: Prenada Media Group

Eriyanto.2002. Analisis Framing; Konstruksi, Ideologi, dan Politik Media. Yogyakarta: LKiS Group

Ibrahim, Idi Subandy. 2007. Budaya Populer Sebagai Komunikasi. Jogjakarta: Jalasutra

Junaedhie, Kurniawan. 1991. Ensiklopedi Pers Indonesia. Jakarta; Gramedia Pustaka

McNair, Brian. 2016. An Introduction to Political Communication. terj, Imam Muttaqien. Pengantar Komunikasi Politik. Cet. I; Bandung: Nusa Media

Nurudin. 2011. Pengantar Komunikasi Massa. Jakarta: Rajawali Pers

Sobur, Alex. 2012. Analisis Teks Media: Suatu Pengantar Untuk Analisis Wacana, 
Analisis Semiotik dan Analisis Framing.

Bandung: Remaja Rosdakarya

Romli, Asep Syamsul. M. 2006. Jurnalistik Praktis Untuk Pemula. Bandung:Remaja Rosdakarya 
DAFTAR TABEL

Tabel 1. Perangkat Framing Model Zhogdang Pan dan Gerald M.Kosicki (Sumber: Eriyanto, 2002, h. 295)

\begin{tabular}{|c|c|c|}
\hline Struktur & Perangkat Framing & Unit yang Diamati \\
\hline $\begin{array}{l}\text { Sintaksis (Syntatical Structures- } \\
\text { Cara wartawan menyusun fakta) }\end{array}$ & Skema Berita & $\begin{array}{l}\text { Headline, lead, latar } \\
\text { informasi, kutipan sumber, } \\
\text { pernyataan, penutup }\end{array}$ \\
\hline $\begin{array}{l}\text { Skrip (Script Structures- Cara } \\
\text { watrawan mengisahkan fakta) }\end{array}$ & Kelangkapan berita & $\begin{array}{l}5 \mathrm{~W}+1 \mathrm{H}(\text { Who, What, When, } \\
\text { Where, Why + How })\end{array}$ \\
\hline $\begin{array}{l}\text { Tematik (Thematic Structures- } \\
\text { Cara wartawan menuliskan } \\
\text { fakta) }\end{array}$ & $\begin{array}{l}\text { - Detail } \\
\text { - Maksud } \\
\text { - Nominalisasi } \\
\text { - Koherensi } \\
\text { - Bentuk kalimat } \\
\text { - Kata ganti }\end{array}$ & $\begin{array}{l}\text { Paragraf, proposisi, kalimat, } \\
\text { hubungan antar kalimat }\end{array}$ \\
\hline $\begin{array}{l}\text { Retoris (Rhetorical Stuctures- } \\
\text { Cara wartawan menekankan } \\
\text { fakta }\end{array}$ & $\begin{array}{l}\text { - Leksikon } \\
\text { - Grafis } \\
\text { - Metafora } \\
\text { - Pengandaian }\end{array}$ & $\begin{array}{l}\text { Kata, idiom, gambar, foto, } \\
\text { grafik }\end{array}$ \\
\hline
\end{tabular}

Tabel 2. Berita Duta Politika Indonesia Door To Door untuk Bur-Nojeng

\begin{tabular}{|c|c|c|}
\hline Perangkat Framing & Unit Analisis & Hasil Pengamatan \\
\hline \multirow[t]{5}{*}{ Sintaksis } & Judul & $\begin{array}{l}\text { Duta Politika Indonesia Door To Door untuk Bur- } \\
\text { Nojeng }\end{array}$ \\
\hline & Lead & $\begin{array}{l}\text { Duta Politika Indonesia (DPI) bakal ikut } \\
\text { menurunkan relawan untuk memenangkan pasangan } \\
\text { Calon Bupati dan Wakil Bupati Takalar, Bur- } \\
\text { Nojeng. }\end{array}$ \\
\hline & Latar informasi & Komentar tim relawan \\
\hline & Kutipan & $\begin{array}{l}\text { Direktur Eksekutif DPI Dedy Alamsyah Mannaroi, } \\
\text { mengatakan Relawan Door To Door Bur- } \\
\text { Nojengakan turun kan langsung ke } 9 \text { kecamatan dan } \\
100 \text { desa }\end{array}$ \\
\hline & Penutup & $\begin{array}{l}\text { Basis kekuatan politik Bur-Nojeng dibalik koalisi } \\
\text { partai besar yaitu Golkar, Demokrat, PAN, PPP, } \\
\text { Hanura, Gerindra, dan PKPI }\end{array}$ \\
\hline \multirow[t]{6}{*}{ Skrip } & What & Pernyataan Relawan Bur-Nojeng \\
\hline & Who & Direktur Eksekutif DPI Dedy Alamsyah \\
\hline & Where & Tanpa menyebut tempat wawancara \\
\hline & When & Selasa, 1/11/2016 \\
\hline & Why & Upaya memenagkan Calon Bupati \\
\hline & How & $\begin{array}{l}\text { Door to door atau turun langsung ke } 9 \text { Kecamatan } \\
\text { dan } 100 \text { Desa }\end{array}$ \\
\hline Tematik & $\begin{array}{l}\text { Paragraf, proposisi, kalimat, } \\
\text { hubungan antar kalimat }\end{array}$ & $\begin{array}{l}\text { Dari awal sampai akhir teks berita ini menonjolkan } \\
\text { sudut pandang simpatisan sehingga membentuk tema } \\
\text { "pencitraan kandidat". Komentar simpatisan Bur- } \\
\text { Nojeng lebih mengedepankan citra petahana dengan } \\
\text { basis dukungan koalisi partai besar }\end{array}$ \\
\hline Retoris & $\begin{array}{l}\text { Kata, idiom, gambar/foto, } \\
\text { grafik }\end{array}$ & $\begin{array}{l}\text { Pemilihan kata "dukungan partai" dari ucapan } \\
\text { narasumber Duta Politika Indonesia (DPI), Dedy } \\
\text { Alamsyah, bermakna mengasosiasikan citra petahana } \\
\text { dengan kekuatan partai besar yang mendukungnya. }\end{array}$ \\
\hline
\end{tabular}

(Sumber : Hasil Olahan Data Primer Penelitian, 2017) 
Tabel 3. Berita Tenri Olle Sebut Syamsari Kitta-Achmad Daeng Se're Calon Bupati Bersih

\begin{tabular}{|c|c|c|}
\hline Perangkat Framing & Unit Analisis & Hasil Pengamatan \\
\hline \multirow[t]{5}{*}{ Sintaksis } & Judul & $\begin{array}{l}\text { Tenri Olle Sebut Syamsari Kitta-Achmad Daeng } \\
\text { Se're Calon Bupati Bersih. }\end{array}$ \\
\hline & Lead & $\begin{array}{l}\text { Wakil Ketua DPW Partai Nasdem Sulsel Tenri Olle } \\
\text { Yasin Limpo mengumpulkan seluruh pengurus DPD } \\
\text { dan DPC Nasdem Takalar di Rumah Juang } \\
\text { Pattalassang, Kabupaten Takalar }\end{array}$ \\
\hline & Latar informasi & Komentar politisi \\
\hline & Kutipan & $\begin{array}{l}\text { Tenri Olle Yasin Limpo mengklaim adanya support } \\
\text { total dari keluarga besar Yasin Limpo untuk } \\
\text { pasangan SK-HD. }\end{array}$ \\
\hline & Penutup & $\begin{array}{l}\text { Tenri Olle Yasin Limpo menginstruksikan kepada } \\
\text { seluruh jajaran struktur partai di tingkat kecamatan, } \\
\text { desa dan kelurahan untuk memulai program door to } \\
\text { door. }\end{array}$ \\
\hline \multirow[t]{6}{*}{ Skrip } & What & $\begin{array}{l}\text { Komentar Kader Partai pro Syamsari Kitta-Achmad } \\
\text { Daeng Se're }\end{array}$ \\
\hline & Who & Wakil Ketua DPW Nasdem, Tenri Olle YL \\
\hline & Where & Rumah Juang Pattallassang Takalar \\
\hline & When & Selasa, $1 / 11 / 2016$ \\
\hline & Why & Konsolidasi internal DPW/DPC Partai Nasdem \\
\hline & How & $\begin{array}{l}\text { Instruksi kepada jajaran struktural door to door } 20 \\
\text { rumah setiap hari }\end{array}$ \\
\hline Tematik & $\begin{array}{l}\text { Paragraf, proposisi, kalimat, } \\
\text { hubungan antar kalimat }\end{array}$ & $\begin{array}{l}\text { Rangkaian paragraf pada teks berita merupakan } \\
\text { pernyataanTenri Olle YL yang mendukung SK-HD, } \\
\text { dimana komentarnya melegitimasi citra SK- } \\
\text { HDsebagai "calon bupati bersih". }\end{array}$ \\
\hline Retoris & $\begin{array}{l}\text { Kata, idiom, gambar/foto, } \\
\text { grafik }\end{array}$ & $\begin{array}{l}\text { Penekanan kata "bersih" dalam kalimat "calon } \\
\text { bupati bersih" yang diucapkan Wakil Ketua DPW } \\
\text { Nasdem Sulsel, Tenri Olle YL, bermaksud } \\
\text { mencitrakan SK-HD sebagai pemimpin berintegritas } \\
\text { dengan pembuktian } \text { track record serta program kerja } \\
\text { yang diklaim bagus dan mensejahterahkan rakyat. }\end{array}$ \\
\hline
\end{tabular}

(Sumber : Hasil Olahan Data Primer Penelitian, 2017) 
Tabel 4. Berita Janji Kampanye Bur-Nojeng di Galesong Utara

\begin{tabular}{|c|c|c|}
\hline $\begin{array}{l}\text { Perangkat } \\
\text { Framing }\end{array}$ & Unit Analisis & Hasil Pengamatan \\
\hline \multirow[t]{5}{*}{ Sintaksis } & Judul & Janji Kampanye Bur-Nojeng di Galesong Utara. \\
\hline & Lead & $\begin{array}{l}\text { Incumbent Pilkada Takalar, Burhanuddin Baharuddin- M Natsir Ibrahim (Bur-Nojeng) } \\
\text { kampanye di Desa Bontolebang, Kecamatan Galesong Utara. Pusat pendaratan ikan ini } \\
\text { akan lebih besar dan lebih maju karena sangat dekat dengan Makassar sehingga } \\
\text { berpotensi untuk berkembang sangat besar apalagi pelelangan ikan yang di Rajawali } \\
\text { telah ditutup }\end{array}$ \\
\hline & $\begin{array}{l}\text { Latar } \\
\text { informasi }\end{array}$ & Orasi politikBurhanuddin \\
\hline & Kutipan & $\begin{array}{l}\text { Burhanuddin berjanji membangun Pusat Pendaratan Ikan (PPI) di Beba, Desa } \\
\text { Bontolebang jika kembali terpilih }\end{array}$ \\
\hline & Penutup & Kutipan pernyataan Burhanuddin \\
\hline \multirow[t]{6}{*}{ Skrip } & What & Orasi politik kandidat dalam kampanye \\
\hline & Who & Calon Bupati Takalar, Burhanuddin Baharuddin \\
\hline & Where & Desa Bontolebang, Kecamatan Galesong Utara \\
\hline & When & Minggu 20/11/2016 \\
\hline & Why & Upaya kandidat meyakinkan masyarakat Takalar \\
\hline & How & Janji membangun Pusat Pendaratan Ikan (PPI) di Beba, Desa Bontolebang \\
\hline Tematik & $\begin{array}{l}\text { Paragraf, } \\
\text { proposisi, } \\
\text { kalimat, } \\
\text { hubungan } \\
\text { antar kalimat }\end{array}$ & $\begin{array}{l}\text { Rangkaian paragraf pada berita ini mewacanakan opini kandidat mengenai janji } \\
\text { politiknya kepada rakyat yang tertuang dalam program serta visi-misi, maupun rencana } \\
\text { aksi kampanye bentukan partai pengusung kandidat }\end{array}$ \\
\hline Retoris & $\begin{array}{l}\text { Kata, idiom, } \\
\text { gambar/foto, } \\
\text { grafik }\end{array}$ & $\begin{array}{l}\text { Pemilihan kata "janji” pada teks berita dimaksudkan untuk meyakinkan khalayak } \\
\text { bahwa Bur-Nojeng memiliki program kerakyatan }\end{array}$ \\
\hline
\end{tabular}

(Sumber : Hasil Olahan Data Primer Penelitian, 2017)

Tabel 5. Berita Syamsari Kitta Janji Naikkan Tunjangan PNS dan Kepala Desa

\begin{tabular}{|c|c|c|}
\hline Perangkat Framing & Unit Analisis & Hasil Pengamatan \\
\hline \multirow[t]{5}{*}{ Sintaksis } & Judul & $\begin{array}{l}\text { Syamsari Kitta Janji Naikkan Tunjangan PNS dan } \\
\text { Kepala Desa. }\end{array}$ \\
\hline & Lead & $\begin{array}{l}\text { Program pasangan calon bupati dan wakil bupati } \\
\text { nomor urut } 2 \text { Syamsari Kitta-Ahmad Se're }\end{array}$ \\
\hline & Latar informasi & Orasi politik Syamsari Kitta \\
\hline & Kutipan & $\begin{array}{l}\text { Kita berani naikkan tunjangan ASN dan perangkat } \\
\text { desa } 100 \text { persen adalah wujud keseriusan kami }\end{array}$ \\
\hline & Penutup & $\begin{array}{l}\text { Kutipan pernyataan Syamsari Kitta yang } \\
\text { menganggappemberian uang makan untuk ASN } \\
\text { mampu meningkatkan roda ekonomi lokal. }\end{array}$ \\
\hline \multirow[t]{6}{*}{ Skrip } & What & Orasi politik kandidat dalam kampanye \\
\hline & Who & Calon Bupati Takalar, Syamsari Kitta \\
\hline & Where & KelurahanSabintang,Kecamatan Pattalassang \\
\hline & When & Sabtu 26/11/2016 \\
\hline & Why & Upaya kandidat meyakinkan masyarakat Takalar \\
\hline & How & $\begin{array}{l}\text { Janji menaikkan tunjangan ASN serta perangkat desa } \\
\text { hingga } 100 \text { persen. }\end{array}$ \\
\hline Tematik & $\begin{array}{l}\text { Paragraf, proposisi, kalimat, } \\
\text { hubungan antar kalimat }\end{array}$ & $\begin{array}{l}\text { Rangkaian paragraf pada berita ini menunjukkan } \\
\text { tema utama yaitu kampanye politik personal } \\
\text { kandidat maupun kampanye kolektif dari partai } \\
\text { pengusung atau tim pemenangan. }\end{array}$ \\
\hline Retoris & Kata, idiom, gambar/foto, grafik & $\begin{array}{l}\text { Kata "Menangkan" sebagai pilihan kata (leksikon) } \\
\text { diartikulasikan oleh kader PKS lebih konkrit yakni } \\
\text { mengirim } 15 \text { kader terbaiknya ke Takalar untuk } \\
\text { memenangkan SK-HD, }\end{array}$ \\
\hline
\end{tabular}

(Sumber : Hasil Olahan Data Primer Penelitian, 2017) 